\title{
Geração de resíduos sólidos em um restaurante de um Hotel da Serra Gaúcha, Rio Grande do Sul, Brasil
}

\author{
Solid waste generation in a hotel restaurant in Serra Gaúcha, \\ Rio Grande do Sul, Brasil
}

Josiane Pistorello', Suzana Maria De Conto², Marcelo Zaro³

口-

\begin{abstract}
RESUMO
Estudos sobre a geração de resíduos sólidos e desperdício de alimentos em restaurantes são importantes e necessários para a gestão gastronômica e definição de planos de gerenciamento de resíduos sólidos. Essa pesquisa avaliou o balanço mássico de um restaurante de um hotel na Região Turística Uva e Vinho no Rio Grande do Sul. Foram coletados dados durante períodos de alta e baixa temporada, caracterizados pela ocorrência ou não de eventos na região (nove semanas intercaladas). Todos os alimentos crus e processados (utilizados no preparo das refeições e oferecidos aos hóspedes) e os resíduos gerados foram quantificados. Constatou-se que o desperdício de alimentos ocorre, em geral, devido à oferta ser maior do que o consumo. Conclui-se sobrea importância do desenvolvimento de estudos direcionados à geração e descarte de resíduos sólidos em restaurantes no sentido de otimizar os procedimentos no planejamento gastronômico, reduzir o desperdício de alimentos e adotar técnicas de reaproveitamento e de tratamento desses resíduos.
\end{abstract}

Palavras-chave: resíduos sólidos; restaurante; desperdício de alimentos.

\begin{abstract}
Studies on the generation of solid waste and food waste in restaurants are important and necessary for the culinary management and the definition of plans for solid waste management. This research evaluated the mass balance of a hotel restaurant in the touristic region Uva e Vinho in Rio Grande do Sul. Data were collected during periods of high and low season, characterized by the occurrence of events in the region (nine weeks interspersed). All raw and processed food (used in the preparation of meals and offered to guests) and waste generated were quantified. It was found that the food waste generally occurs because the supply is larger than the consumption. We conclude on the importance of the development of studies directed to the generation and disposal of solid waste in restaurants in order to optimize the procedures in the gastronomic planning, reduce food waste and adopt techniques of reuse and treatment of this residues.
\end{abstract}

Keywords: solid waste; restaurant; wastage.

\section{INTRODUÇÃO}

O desperdício de alimentos, a geração de resíduos sólidos e a falta de um plano de gerenciamento adequado dos mesmos tem se tornado um problema cada vez maior no setor gastronômico. No caso do desperdício de alimentos, além da geração de resíduos orgânicos, outros problemas podem ser apontados: desperdício de água e energia, que são recursos utilizados para o cultivo e processamento de alimentos; aplicação desnecessária de agroquímicos em alimentos que não são consumidos; desmatamento e uso de grandes extensões de terra para o plantio de alimentos e criação de animais para corte e leite; aumento de preços dos alimentos pelo varejo e restaurantes, que consideram os resíduos alimentares gerados nas suas planilhas de custos; desperdício de recursos financeiros que poderiam ser aplicados em outras áreas; escassez de alimentos, que afeta principalmente as regiões mais pobres do planeta; empobrecimento de solos devido a técnicas de agricultura inapropriadas, entre outros (IMechE, 2013).

Entre os geradores de resíduos dessa natureza destacam-se os restaurantes pelos serviços oferecidos (FONSECA \& BORGES, 2006; OKAZAKI; TURN; FLACHSBART, 2008). Nesse sentido, alguns questionamentos merecem ser feitos: Que critérios são adotados pelos restaurantes para definir os cardápios? A dimensão ambiental é contemplada no planejamento das refeições? Os conceitos de tecnologia mais limpa são

Trabalho realizado na Universidade de Caxias do SUL (UCS) - Caxias do Sul (RS), Brasil.

'Mestranda em Recursos Hídricos e Saneamento Ambiental pela Universidade Federal do Rio Grande do Sul (UFRGS). Engenheira Ambiental da Companhia Riograndense de Saneamento (CORSAN) - Porto Alegre (RS), Brasil.

2Doutora em Educação pela Universidade Federal de São Carlos (UFSCar). Docente no Centro de Ciências Exatas e Tecnologia, no Mestrado em Turismo e no Mestrado Profissional em Engenharia e Ciências Ambientais da UCS - Caxias do Sul (RS), Brasil.

${ }^{3}$ Mestre em Engenharia de Processos e Tecnologias pela UCS. Engenheiro Ambiental pela UCS - Caxias do Sul (RS), Brasil.

Endereço para correspondência: Suzana Maria De Conto - Rua Francisco Getúlio Vargas, 1130 - 95070-560 - Caxias do Sul (RS), Brasil - E-mail: smcmande@ucs.br Recebido: 08/04/14 - Aceito: 17/11/14 - Reg. ABES: 133231 
empregados nos restaurantes? A realização do balanço de massa (identificação da relação entre a quantidade de produtos utilizados no preparo de alimentos, consumo dos alimentos e geração de resíduos sólidos) é observada pelos gestores de restaurantes como uma etapa importante a ser contemplada na gestão desses estabelecimentos? A gestão de resíduos sólidos é contemplada na gestão de empreendimentos gastronômicos? Essas entre outras perguntas são importantes para a definição de planos de gerenciamento de resíduos sólidos gerados no âmbito dos restaurantes como também para investigar a origem de desperdícios de alimentos.

Nos restaurantes, em geral, a variedade e a quantidade de alimentos ofertados ultrapassam a necessidade de consumo, observando-se a ocorrência de sobras e de desperdício, contribuindo para um incremento na geração de resíduos sólidos (WRAP, 2013; NASPOLINI et al., 2009). Assim, é fundamental o planejamento adequado dos cardápios e das refeições, implementando medidas preventivas de geração de resíduos sólidos nesses serviços de alimentação.

"Resíduos sólidos", de acordo com a Política Nacional de Resíduos Sólidos são definidos como:

material, substância, objeto ou bem descartado resultante de atividades humanas em sociedade, a cuja destinação final se procede, se propõe proceder ou se está obrigado a proceder, nos estados sólido ou semi-sólido, bem como gases contidos em recipientes e líquidos cujas particularidades tornem inviável o seu lançamento na rede pública de esgotos ou em corpos d'água, ou exijam para isso soluções técnica ou economicamente inviáveis em face da melhor tecnologia disponível (BRASIL, 2010).

O termo "sobras" é assim definido por Viera (2004, p. 16):

sobras são representadas pela quantidade de produtos aproveitáveis que não foi utilizada em um processo de produção, mas que poderá ser utilizada em outro processo, mesmo diferente do primeiro.

Uma boa alternativa para reduzir o desperdício de alimentos é planejar a quantidade de alimentos perecíveis, devendo ter suas quantidades reguladas pela necessidade de consumo. Ao partir do diagnóstico (realização de balanços mássicos), pode-se ter uma visão mais detalhada da elaboração das refeições em um restaurante, identificando a quantidade de alimentos e produtos antes do preparo, os desperdícios e os resíduos gerados durante o preparo e após o consumo dos alimentos. A partir dessa primeira etapa, é possível propor medidas preventivas de geração de resíduos sólidos e/ou de reaproveitamento de alimentos.

O presente estudo visa avaliar a geração de resíduos sólidos a partir da realização de um balanço mássico dos alimentos considerando as refeições ofertadas na forma de café da manhã, à la carte, buffet e coffee-break em um restaurante de um hotel localizado na Região Turística Uva e Vinho do estado do Rio Grande do Sul.

\section{Geração de resíduos sólidos em unidades de alimentação}

As projeções indicam que, em 2075, a população mundial pode chegar a 9,5 bilhões de pessoas, o que significa um aumento de aproximadamente três bilhões de pessoas em relação à população mundial atual. Atualmente, são produzidos em torno de 4 bilhões de toneladas de alimentos por ano. Porém, estima-se que entre $30-50 \%$ de toda a comida produzida no mundo (1,2-2 bilhões de toneladas) seja transformada em resíduos sólidos. Portanto, políticas sociais, econômicas e ambientais precisam ser construídas hoje para garantir a sustentabilidade no futuro (IMechE, 2013).

De acordo com IPEA (2009), o Brasil está entre os 10 países que mais desperdiçam comida no mundo, onde aproximadamente 35\% de toda a produção agrícola é descartada como resíduos sólidos. Ainda IPEA destaca, com isso, que mais de 10 milhões de toneladas de alimentos poderiam abastecer 54 milhões de brasileiros que vivem na linha da pobreza.

Em âmbito domiciliar, são diversas as razões que levam ao desperdício. Williams et al. (2012) realizaram uma pesquisa com 61 famílias da Suécia. As famílias foram convidadas a observar a sua geração de resíduos e responder a um questionário sobre os seus padrões de descarte. Ambos os grupos indicaram que quase $50 \%$ da sua comida é descartada por ter estragado e em torno de $25 \%$ porque foi preparada em uma quantidade maior que a consumida. $\mathrm{O}$ tamanho de embalagens e a dificuldade em esvaziar algumas delas, devido ao seu design, também foram relatadas pelos respondentes como motivos para terem desperdiçado alimentos.

Teixeira et al. (2006) afirmam que o desperdício de alimentos em uma unidade de alimentação e nutrição é proveniente de sobras de alimentos (alimentos preparados e não distribuídos) e restos (alimentos distribuídos e não consumidos). De acordo com os autores, os alimentos preparados e não distribuídos são provenientes do planejamento inadequado do número de refeições a serem produzidas, da frequência diária dos usuários, das preferências alimentares, do treinamento de funcionários na produção e no porcionamento.

Em uma unidade de autogestão, Bradacz (2003) ainda observa que os maiores desperdícios ocorrem em períodos de contratação de mão-de-obra temporária, a qual não recebeu treinamento e conscientização de uma política de desperdício zero e também quando se tem uma maior produção de refeições. A autora também realizou um estudo em uma unidade de alimentação e nutrição (UAN) do tipo concessionária, onde a refeição é o principal produto a ser comercializado, por isso, essa empresa dá importância a implantação de programas de redução do desperdício de alimentos, mesmo que os resultados não sejam favoráveis. Nesta unidade, o desperdício está relacionado com a qualidade e a sua produtividade e a empresa optou por informar a quantidade de comida desperdiçada por 
bandeja, a fim de diminuir ainda mais o desperdício, mostrando para o comensal que ele é um elemento causador de desperdício.

Em pesquisa realizada por Sonnino e McWilliam (2011) em três hospitais do País de Gales foi diagnosticado que uma quantidade muito grande de alimentos era preparada para o número de pacientes atendidos. De acordo com os autores isso ocorre, por exemplo, por falta de capacitação dos funcionários. No que se refere ao desperdício no prato, ficou evidente a falta de atenção dos funcionários em ofertar alimentos do gosto dos pacientes. Porções em quantidades pré-estabelecidas e oferta automática de verduras e legumes contribuem para aumentar o desperdício. Finalmente, os resultados indicam que o desperdício de alimentos nos hospitais variou de 19 a 66\%. Os maiores desperdícios foram constatados em refeições ofertadas a pessoas idosas, com porcentagens de desperdício que ultrapassaram $30 \%$ do total de alimentos oferecidos. Em um dos hospitais, por exemplo, para cada $265 \mathrm{~g}$ de alimentos servidos, em média $103 \mathrm{~g}$ foram deixados no prato.

Ao avaliarem a geração de resíduos de alimentos em diversos estabelecimentos do Havaí (4.854), Okazaki, Turn e Flachsbart (2008) obtiveram que restaurantes representavam uma das categorias que mais gerava resíduos de alimentos (103.617 toneladas/ano), atrás apenas do setor de varejo. Na pesquisa, a maioria dos dirigentes de estabelecimentos indicou não promover técnicas de reciclagem dos resíduos alimentares, indicando diversas razões: a separação dos resíduos alimentares dos outros resíduos consome muito tempo ou envolve custos; dificuldades de armazenamento, transporte e logística; problemas do ponto de vista sanitário e de saúde; não geração de resíduos alimentares ou pequena quantidade gerada; não sabiam que os resíduos alimentares poderiam ser reciclados; falta de oportunidade para reciclar; não têm permissão para adotar práticas de reciclagem de resíduos alimentares. No mesmo estudo, foi estimado que a geração de resíduos alimentares no Havaí é de em torno de 336,5 toneladas anuais ou 0,66 kg/pessoa/dia.

Fonseca e Borges (2006) afirmam que, na hotelaria, os restaurantes são os grandes produtores de resíduos, visto que a produção daquilo que oferecem ao cliente envolve um alto nível de processamento da matéria prima, a qual na maioria das vezes chega ao local in natura e é destinada à preparação de receitas que demandam apenas parte de sua composição. Os autores ainda apresentam que o controle quanto ao volume de resíduo orgânico que deixa os estabelecimentos, fazendo uma relação do que é de fato produzido e vendido, é quase que inexistente. No entanto, o próprio público frequentador dos estabelecimentos de hospitalidade, como hotéis, bares e restaurantes, vêm fazendo uma série de cobranças acerca das políticas de gestão ambiental dos estabelecimentos, o que se deve ao fato da maior acessibilidade à informação relacionada ao meio ambiente e práticas de sustentabilidade.

Enfim, constata-se que os problemas decorrentes da geração de resíduos sólidos e desperdício de alimentos em restaurantes é um problema de gestão desses empreendimentos. A importância de contemplar a dimensão ambiental no planejamento das atividades gastronômicas é indiscutível para minimizar os impactos ambientais decorrentes dessa atividade. Nesse sentido, são necessárias ações concretas urgentes no que tange ao controle do desperdício de alimentos, visto que esse é um problema antigo.

Para um bom desempenho das unidades de alimentação e nutrição é importante a realização de um planejamento efetivo considerando os seguintes fatores: a quantidade de refeições a ser preparada, o número de comensais, o cardápio diário, a estação climática, a sazonalidade da produção de hortifrutigranjeiros, a política de compra dos produtos pelas empresas, as características dos alimentos que influenciam no tempo e forma de armazenamento, o consumo de água e de energia na preparação dos alimentos, a utilização de produtos pré-prontos, a quantidade de sobras, a geração de resíduos e de desperdícios, entre outros fatores (TEIXEIRA et al., 2006; MEZOMO, 2002; ABREU; SPINELLI; PINTO, 2007).

Deve-se considerar também o tipo de refeição e clientela atendida, além de ser importante realizar uma avaliação das sobras das refeições. A quantidade de sobras deve ser proporcional ao número de refeições servidas, sendo que o excesso das mesmas pode indicar falhas de porcionamento das refeições ou mesmo no seu planejamento, no que diz respeito à definição das necessidades nutricionais (TEIXEIRA et al., 2006).

A implementação de um projeto de minimização de resíduos, embora possa exigir um capital adicional para investimento, pode trazer diversos benefícios, conforme destacam Crittenden e Kolaczkowski (1995):

- redução de custos com manejo, transporte, tratamento e destino final dos resíduos;

- redução do espaço para estoque dos resíduos, o qual pode ser aproveitado para fins mais úteis;

- redução dos custos de produção ao se utilizar menos insumos e energia;

- reduz riscos, em geral, aos funcionários;

- reduz os impactos ambientais do empreendimento; e

- melhora a imagem da empresa diante de clientes, funcionários e comunidade em geral.

Para que os programas de minimização de resíduos sejam efetivos é necessário que exista comprometimento da alta direção do empreendimento; a definição de uma política institucional e definição de estratégias para a sua implementação; provisão suficiente de recursos; um programa de treinamento e motivação de pessoal; e estímulo de iniciativas que visam à implantação de projetos de minimização da geração de resíduos (CRITTENDEN \& KOLACZKOWSKI, 1995).

Além disso, Bradacz (2003) relata que os programas de redução de desperdício de alimentos, para serem completos e efetivos, devem combinar mudanças comportamentais, educação e principalmente conscientização, tanto de comensais como de manipuladores de alimentos. Considerando que a informação é uma variável que determina o comportamento das pessoas em relação ao manejo de resíduos 
sólidos, é importante que a mesma seja de qualidade, disponibilizada de forma contínua e que alcance também a comunidade que vive no entorno (MANDELLI, 1997). Nesse sentido, destaca-se a importância do desenvolvimento de programas de educação ambiental no sentido de controlar e combater o desperdício de alimentos no setor gastronômico.

\section{METODOLOGIA}

Este estudo foi desenvolvido em um restaurante de um hotel com 90 unidades habitacionais e 187 leitos, localizado na Região Turística Uva e Vinho, no município de Caxias do Sul (RS). Inicialmente, foram identificados os cardápios, a tipologia e a quantidade de alimentos utilizados na preparação das refeições. O restaurante oferecia café da manhã a todos os hóspedes, refeições à la carte conforme a solicitação do cliente e coffee-breaks nos eventos realizados no hotel. O número total de refeições oferecidas durante as nove semanas de coleta de dados foi de 8.389 (4.316 na alta temporada e 4.073 na baixa temporada).

As semanas de baixa temporada (cinco) caracterizaram-se pela não realização de eventos na região. A alta temporada (quatro semanas) foi caracterizada pela existência de eventos de negócios ou feiras na região. As semanas de alta temporada foram selecionadas quando ocorreram os seguintes eventos: Feira Brasileira da Mecânica e Automação Industrial (Febramec); Feira de Subcontratação e Inovação Industrial (Mercopar); Festa Nacional da Uva e Movelsul Brasil.

Os eventos que determinaram as semanas de alta temporada, com exceção da Festa Nacional da Uva caracterizam-se por serem feiras de negócios e que apresentam as inovações e tecnologias voltadas para setores industriais ou de serviços específicos. Já a Festa Nacional da Uva é um evento cultural que atrai diversos turistas, visto que divulga os costumes e a gastronomia da Serra Gaúcha, predominantemente da colonização italiana. Além disso, a Festa conta com uma feira de negócios.

Para a realização do balanço mássico foram realizadas as pesagens dos itens elencados a seguir, considerando cada uma das refeições e os turnos de trabalho:

- alimentos utilizados no preparo das refeições;

- alimentos oferecidos no café da manhã;

- alimentos oferecidos no café da manhã e que não foram consumidos (intocados nas bandejas);

- alimentos oferecidos nos pratos à la carte;

- alimentos oferecidos nos coffee-breaks;

- alimentos oferecidos nos coffee-breaks e que não foram consumidos (intocados nas bandejas);

- resíduos gerados no preparo em cada uma das refeições;

- resíduos gerados em cada uma das refeições pelos clientes.

Nas pesagens dos resíduos foram considerados os orgânicos e os potencialmente recicláveis (seletivo).
As pesagens dos alimentos e o registro em planilhas foram realizados pelas cozinheiras (colaboradoras). Para tal, todas as orientações e esclarecimentos foram realizados pelos pesquisadores em reuniões específicas, sendo as colaboradoras devidamente orientadas pelos pesquisadores. Para o registro foram disponibilizadas planilhas que foram estruturadas especificamente para cada turno e cada tipo de refeição. Os instrumentos de coleta de dados (planilhas) foram construídos contendo todas as informações necessárias para o melhor entendimento dos procedimentos (passo a passo) a serem seguidos pelas colaboradoras (pesagem e registro dos alimentos em planilhas próprias e separação e identificação com etiquetas dos resíduos gerados). Os resíduos sólidos foram pesados pelos pesquisadores. Todos os dados coletados foram tabulados diariamente em planilhas do Excel e depois organizados por semanas, considerando os períodos de baixa e de alta temporada na hotelaria do município. Nos Resultados são apresentados o somatório de todas as pesagens dos períodos de alta (28 dias correspondentes a quatro semanas) e baixa temporada (35 dias correspondentes a cinco semanas).

\section{RESULTADOS E DISCUSSÃO}

O cardápio oferecido no café da manhã incluía frutas, iogurtes, salada de fruta, pães, bolos, salgados, tortas, pudim, leite, café, sucos, cereais, queijos, embutidos, mel, geléias, goiabada, margarina e manteiga. Esses dois últimos produtos eram oferecidos em embalagens individuais. Nas refeições à la carte, o restaurante dispunha de um cardápio que incluía saladas, sopas, massas, pizzas, sanduíches, panquecas, omeletes e carnes. Já o cardápio dos coffee-breaks era elaborado com base na demanda da empresa que contrata esse serviço para seus eventos realizados no hotel, podendo contemplar sanduíches, bolos, salgados, café, sucos e água.

O preparo e oferta de alimentos no hotel ocorriam da seguinte maneira:

- Café da manhã: os alimentos (bolos, pães, salgados, entre outros), preparados no dia anterior, eram aquecidos na manhã seguinte e organizados em bandejas para oferta na forma de buffet.

- À la carte: o restaurante dispunha de um cardápio à disposição dos clientes (hóspedes ou não). O preparo dos alimentos utilizados nesses pratos ocorria no turno da tarde, sendo posteriormente congelados. No momento que um determinado prato era solicitado, as colaboradoras realizavam a sua montagem e aquecimento.

- Coffee-breaks: eram ofertados nos eventos que ocorriam nas salas de reuniões do hotel. Geralmente eram ofertados na metade da manhã e da tarde, dependendo da duração e da contratação desse serviço. O preparo era realizado de acordo com a demanda.

Na Figura 1 é apresentado um fluxograma do balanço mássico com as informações gerais obtidas para a refeição café da manhã. Na Tabela 1 são apresentados os dados do balanço mássico obtidos para 
essa refeição, sendo que estão organizados considerando as semanas de baixa e de alta temporada.

Por meio desses dados, observa-se que do total de alimentos utilizados no preparo do café da manhã (3,76 toneladas), 73,0\% desses alimentos foram oferecidos aos hóspedes $(2.743,110 \mathrm{~kg})$. Dessa parcela oferecida constata-se que 49,2\% não foi consumida pelos hóspedes, permanecendo intocada nas bandejas, sendo que $37,3 \%$ dos alimentos oferecidos foram consumidos.

Em relação aos resíduos sólidos gerados nessa refeição, observa-se que $21,3 \%$ de todos os alimentos utilizados em preparações acabam sendo descartados ainda na fase de processamento, e 13,5\% dos alimentos ofertados aos hóspedes tornam-se resíduos. Destaca-se que este percentual inclui as embalagens dos alimentos.
Conforme os dados apresentados na Tabela 1, observa-se que na alta temporada é utilizada uma quantidade maior de alimentos no preparo em virtude da maior ocupação do meio de hospedagem. A quantidade de alimentos oferecidos, assim como de alimentos consumidos também é superior na alta temporada, conforme pode ser observado nas Tabelas 1 e 2. Destaca-se ainda que a alta temporada corresponde a 28 dias e a baixa temporada a 35 dias. Cabe observar que na baixa temporada, a quantidade de alimentos que são higienizados e preparados e que acabam não sendo oferecidos aos hóspedes é maior. Verifica-se também que é maior a quantidade de alimentos que é oferecida, porém não consumida, em comparação com a alta temporada.

Em ambas as temporadas, observa-se que é oferecida aos hóspedes uma quantidade de alimentos superior à demanda, que corresponde a

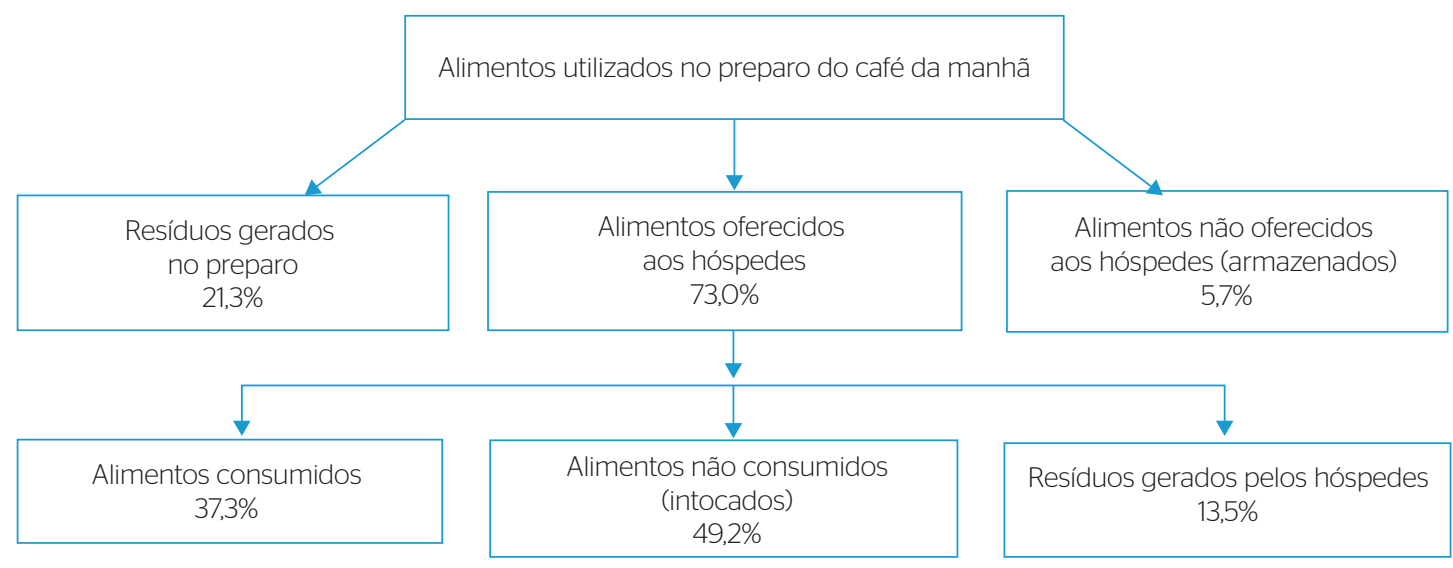

Figura 1 - Fluxograma do balanço mássico da refeição café da manhã.

Tabela 1 - Balanço mássico do café da manhã.

\begin{tabular}{l|c|c|c}
\multirow{2}{*}{ Café da manhã } & \multicolumn{3}{|c}{ Quantidade (kg) } \\
\cline { 2 - 4 } & $\begin{array}{c}\text { Alta } \\
\text { temporada }\end{array}$ & $\begin{array}{c}\text { Baixa } \\
\text { temporada }\end{array}$ & Total \\
\hline $\begin{array}{l}\text { Alimentos utilizados no } \\
\text { preparo }\end{array}$ & $1.970,02$ & $1.786,99$ & $3.757,01$ \\
\hline $\begin{array}{l}\text { Alimentos não oferecidos aos } \\
\text { hóspedes }\end{array}$ & 78,93 & 131,18 & 210,11 \\
\hline Resíduos do preparo & 453,13 & 350,65 & 803,79 \\
\hline $\begin{array}{l}\text { Alimentos oferecidos aos } \\
\text { hóspedes }\end{array}$ & $1.437,96$ & $1.305,14$ & $2.743,11$ \\
\hline Alimentos consumidos & 587,10 & 441,33 & $1.028,43$ \\
\hline $\begin{array}{l}\text { Alimentos não consumidos } \\
\text { (intocados) }\end{array}$ & 654,05 & 689,38 & $1.343,44$ \\
\hline $\begin{array}{l}\text { Resíduos gerados pelos } \\
\text { hóspedes }\end{array}$ & 196,80 & 174,43 & 371,23 \\
\hline
\end{tabular}

Tabela 2 - Balanço mássico da refeição à la carte.

\begin{tabular}{l|c|c|c}
\multirow{2}{*}{ A la carte } & \multicolumn{3}{|c}{ Quantidade (kg) } \\
\cline { 2 - 4 } & $\begin{array}{c}\text { Alta } \\
\text { temporada }\end{array}$ & $\begin{array}{c}\text { Baixa } \\
\text { temporada }\end{array}$ & Total \\
\hline $\begin{array}{l}\text { Alimentos utilizados no } \\
\text { preparo }\end{array}$ & 633,32 & 435,71 & $1.069,03$ \\
\hline $\begin{array}{l}\text { Alimentos oferecidos aos } \\
\text { clientes }\end{array}$ & 528,94 & 360,17 & 889,12 \\
\hline Resíduos do preparo & 104,37 & 75,54 & 179,91 \\
\hline Alimentos consumidos & 401,43 & 307,07 & 708,50 \\
\hline $\begin{array}{l}\text { Resíduos gerados pelos } \\
\text { Clientes }\end{array}$ & 127,51 & 53,10 & 180,62 \\
\hline
\end{tabular}


45,5 e 52,8\% do total de alimentos oferecidos na alta e baixa temporada, respectivamente. Observa-se que nesta refeição foram gerados $1.175 \mathrm{~kg}$ de resíduos sólidos, tanto provenientes do preparo como gerados pelo hóspede. A maior parcela foi gerada na etapa de preparo dos alimentos, cuja principal contribuição é devido à higienização de frutas.

Venzke (2006), em sua investigação, apresenta os resultados obtidos na análise da atividade produtiva de um restaurante industrial com o enfoque da produção mais limpa. Pela análise do processo produtivo, Venzke (2006) obteve que a etapa de higienização dos alimentos de origem vegetal é a que mais gera resíduos orgânicos. Nessa etapa os alimentos são descascados, cortados e lavados. A coleta de dados, segundo o autor, foi realizada em uma semana envolvendo os alimentos de origem vegetal e a partir dos dados pode-se obter o aproveitamento de cada alimento. Para o autor, o aproveitamento pode ser definido como a relação entre peso do alimento já processado e antes do processamento.

O restaurante em que foi realizada a pesquisa por Venzke (2006) servia cerca de mil refeições por dia em uma empresa de componentes automotivos. No estudo foi constatado que, a cada cinco dias, eram geradas 901,55 gramas de resíduos orgânicos por refeição servida. Ao considerar-se 22 dias úteis no mês e as 1.000 refeições servidas diariamente, gerava-se em um mês 3,97 toneladas de resíduos orgânicos, apenas no processo de higienização dos alimentos. A principal causa apontada para essa geração foi a falta do controle das matérias primas, o que gera desperdícios e uma quantidade maior de resíduos. $\mathrm{O}$ autor sugere que o restaurante substitua os produtos in natura por alimentos previamente higienizados, buscando reduzir assim os resíduos e o consumo de água, sempre tendo presente o conceito de produção mais limpa. Como vantagens da utilização dos alimentos previamente higienizados, o autor destaca a maior facilidade em aplicar a compostagem e instalar sistemas de reutilização da água usada na limpeza dos alimentos, visto que os resíduos ficariam concentrados na unidade processadora, que operaria em escala de produção.

Além disso, os alimentos não utilizáveis, segundo o autor, não devem ser tratados como resíduos, mas como matéria-prima com alto valor nutritivo, que pode vir a ser utilizada na elaboração de um novo produto. Porém, um problema não abordado por Venzke (2006) é que, em virtude dos alimentos higienizados serem embalados, a utilização desse tipo de produto gera o descarte de diferentes tipos de embalagens. Assim, a fração orgânica pode ser gerada numa quantidade reduzida, porém resultando numa grande geração de embalagens descartáveis.

$\mathrm{Na}$ Figura 2 é apresentado o fluxograma do balanço mássico com as informações gerais obtidas para a refeição à la carte e na Tabela 2 são apresentados os dados do balanço mássico obtidos para essa refeição, organizados considerando as semanas de baixa e alta temporadas.

Dos dados constantes na Figura 2 e Tabela 2 observa-se que do total de alimentos utilizados no preparo dos pratos à la carte (1,07 tonelada), a maior parcela, $83,2 \%$, são ofertados aos clientes, sendo que $16,8 \%$ são descartados como resíduos. Já, ao considerar os alimentos oferecidos ao cliente, constata-se que a parcela mais representativa refere-se aos alimentos que são consumidos (79,7\%). Nas refeições à la carte os alimentos eram preparados conforme a demanda, desta forma não há alimentos preparados e não ofertados.

Observa-se que, diferentemente do que ocorre no café da manhã, a parcela de alimentos ofertados e consumidos pelo cliente é maior, sendo possível concluir que ocorre um menor desperdício. Esse fato deve-se a dinâmica dessa refeição no restaurante do meio de hospedagem, visto que os pratos à la carte são ofertados com base na demanda dos clientes. Estes solicitam suas refeições a partir de um cardápio pré-estabelecido, estando ciente do que lhe será oferecido. A constatação vai de encontro com os resultados da pesquisa realizada por Youngs, Nobis e Town (1983) ainda na década de 1980, onde uma menor geração de resíduos alimentares foi atribuída ao uso de alimentos pré-preparados, menus restritos, cobrança por cada refeição feita pelos clientes e existência de procedimentos de controle estabelecidos pelos hotéis.

Na Figura 3 é apresentado o fluxograma do balanço mássico da refeição na forma de buffet. Os dados apresentados na Figura 3 referem-se a um jantar que foi ofertado na forma de buffet no meio de hospedagem. É importante frisar que não foram realizadas outras amostragens relacionadas a esse tipo de refeição, visto que a mesma não se repetiu durante o período de coleta de dados.

Observa-se que de forma semelhante a outras refeições, tendo como base o total de alimentos, verifica-se uma disparidade no que se refere aos alimentos consumidos, que representaram apenas $27,4 \%$. Os clientes geraram resíduos equivalentes a 17,4\% dos alimentos oferecidos, sendo que a maior parte $(55,2 \%)$ acabou não sendo consumida, permanecendo intocada nas bandejas.

Comparando esses índices à refeição café da manhã, conclui-se que o índice de rejeição foi maior no jantar, visto que a parcela de alimentos consumidos foi inferior ao valor obtido no café da manhã, que representou 37,3\% dos alimentos ofertados. Essa desigualdade entre

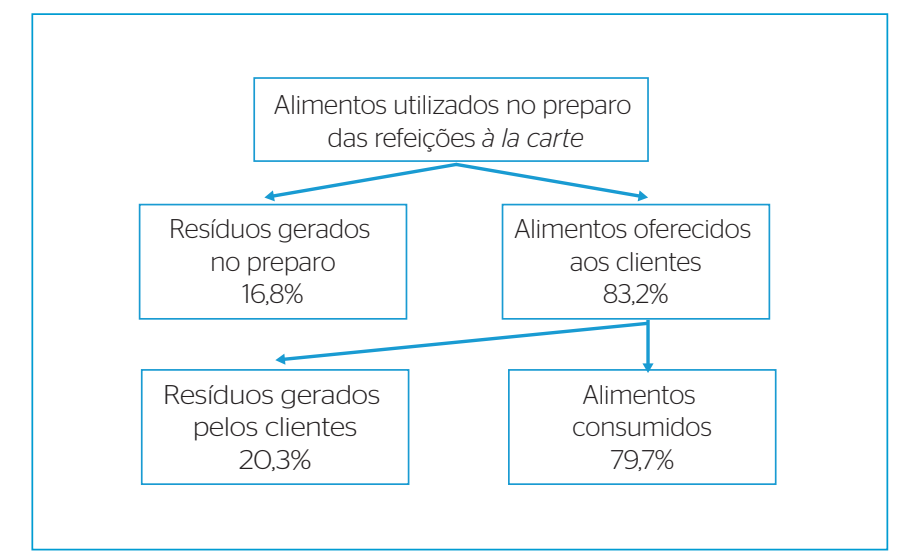

Figura 2 - Fluxograma do balanço mássico da refeição à la carte. 
oferta e demanda pode ter ocorrido devido a um planejamento não condizente ao número de clientes.

O meio de hospedagem também oferecia o serviço de coffee-breaks para os eventos que ocorrem em suas salas de reuniões. Na Figura 4 é apresentado o fluxograma do balanço mássico referente a essa refeição e na Tabela 3 os dados sistematizados, considerando baixa e alta temporada.

Pode-se observar que, nos coffee-breaks, foram utilizados para o preparo $80,61 \mathrm{~kg}$ de alimentos, dos quais $8,1 \%$ foram descartados como resíduos sólidos e o restante foi oferecido aos participantes dos eventos. De forma semelhante ao café da manhã, esses alimentos são ofertados em bandejas, sendo possível constatar que uma parcela dos alimentos oferecidos (14,6\%) acabou não sendo consumida, retornando intocada. Constata-se também que, nos coffee-breaks, têm-se o maior índice de alimentos consumidos com base na quantidade de alimentos ofertados $(84,3 \%)$ em comparação com o café da manhã, as refeições à la carte e o buffet.

Na Tabela 4 é apresentado um resumo das quantidades de resíduos sólidos gerados no preparo da alimentação e pelos hóspedes/clientes após a refeição. A Figura 5 apresenta as frações de resíduos orgânicos e potencialmente recicláveis considerando cada uma das refeições. O resíduo seletivo é composto de embalagens de vidro, plástico, papel, papelão, metal ferroso e não-ferroso.

Ao analisar os dados de geração de resíduos sólidos das Tabelas 1 a 4, é possível observar que a produção maior ocorre na alta temporada. Considerando as refeições (café da manhã, à la carte e coffee-break), a geração per capita na alta temporada foi de $204,7 \mathrm{~g}$ de resíduos sólidos/refeição e, na baixa temporada, foi de 161,8 g de resíduos sólidos/refeição.

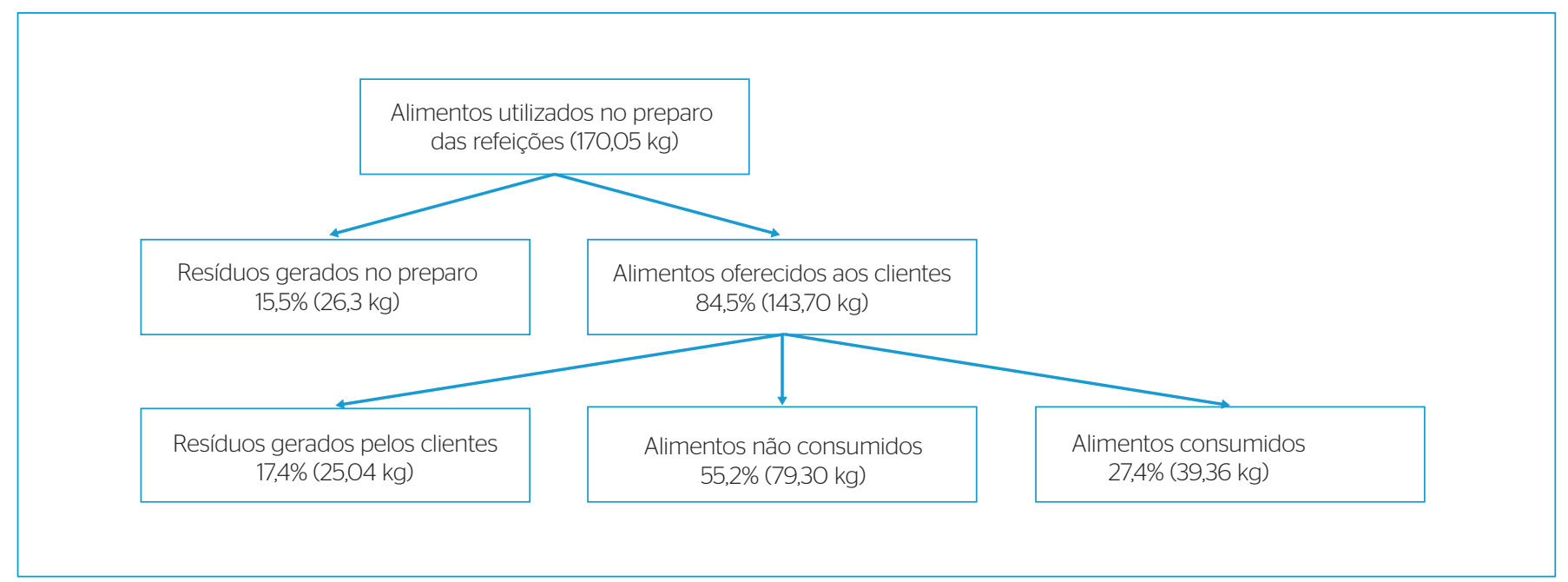

Figura 3 - Fluxograma do balanço mássico da refeição buffet.

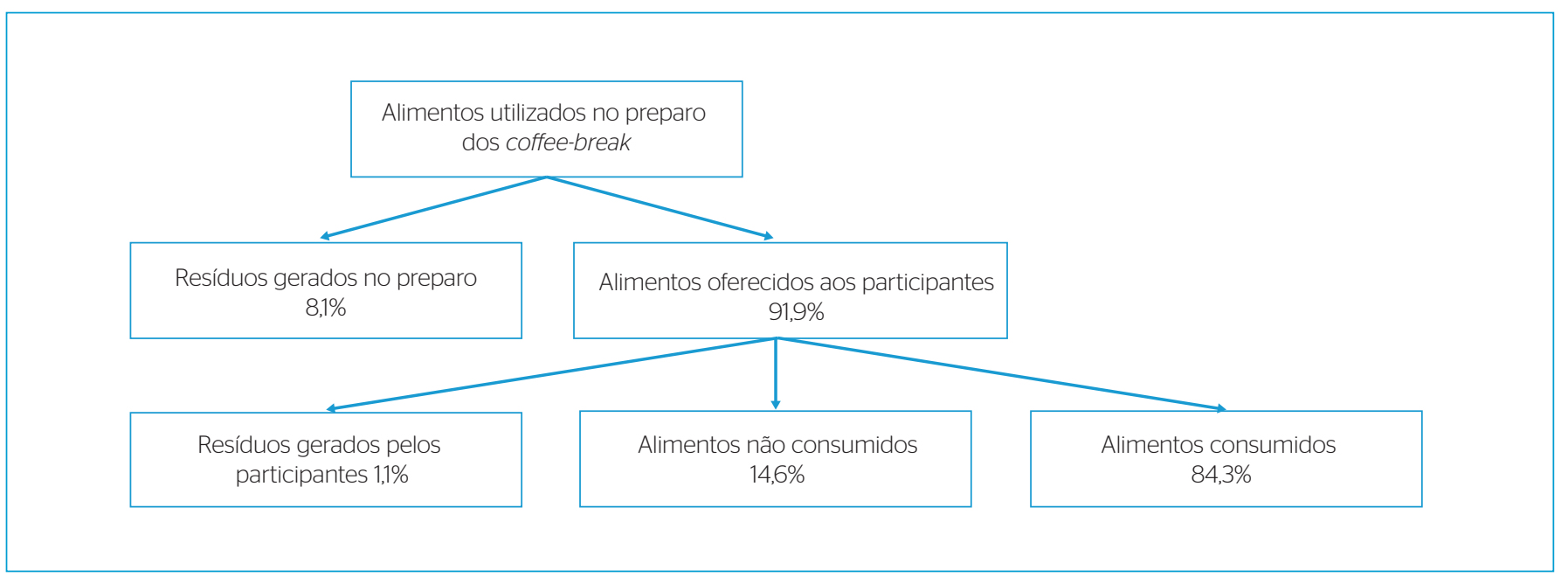

Figura 4 - Fluxograma do balanço mássico da refeição coffee-break. 
Constata-se que a maior parcela dos resíduos sólidos gerados no restaurante refere-se à matéria orgânica putrescível, variando de 84,1 a $92,7 \%$ do montante gerado. O café da manhã é a refeição com a maior geração de resíduos orgânicos $(92,7 \%)$ nas semanas amostradas tendo como base a totalidade de resíduos gerados no preparo das refeições e gerados pelos clientes. Considerando o período de amostragem, foram gerados $1.444,06 \mathrm{~kg}$ de resíduos

Tabela 3 - Balanço mássico da refeição coffee-break.

\begin{tabular}{l|c|c|c}
\multirow{2}{*}{ Coffee-break } & \multicolumn{3}{|c}{ Quantidade (kg) } \\
\cline { 2 - 4 } & $\begin{array}{c}\text { Alta } \\
\text { temporada }\end{array}$ & $\begin{array}{c}\text { Baixa } \\
\text { temporada }\end{array}$ & Total \\
\hline Alimentos utilizados no preparo & 37,79 & 42,82 & 80,61 \\
\hline $\begin{array}{l}\text { Alimentos oferecidos aos } \\
\text { participantes }\end{array}$ & 36,37 & 37,69 & 74,07 \\
\hline Resíduos do preparo & 1,41 & 5,12 & 6,54 \\
\hline $\begin{array}{l}\text { Alimentos consumidos } \\
\text { Alimentos não consumidos } \\
\text { (intocados) }\end{array}$ & 30,89 & 31,53 & 62,42 \\
\hline $\begin{array}{l}\text { Resíduos gerados pelos } \\
\text { hóspedes }\end{array}$ & 5,00 & 5,81 & 10,81 \\
\hline
\end{tabular}

Tabela 4 - Geração de resíduos sólidos no restaurante.

\begin{tabular}{l|r|r|r|r|r}
\multirow{2}{*}{ Refeições } & \multicolumn{5}{c}{ Quantidade (kg) } \\
\cline { 2 - 5 } & \multicolumn{2}{|c|}{ Preparo } & \multicolumn{2}{c}{ Hóspede/Cliente } & \multirow{2}{*}{ Total } \\
\cline { 2 - 5 } & Orgânico & Seletivo & Orgânico & Seletivo & \\
\hline Café da manhã & 760,58 & 43,22 & 328,78 & 42,46 & $1.175,04$ \\
\hline A la carte & 148,60 & 31,31 & 154,62 & 26,01 & 360,54 \\
\hline Buffet & 21,68 & 4,67 & 23,11 & 1,94 & 51,40 \\
\hline Coffee-break & 6,34 & 0,21 & 0,35 & 0,48 & 7,38 \\
\hline TOTAL & 937,20 & 79,41 & 506,86 & 70,89 & $1,594,36$ \\
\hline
\end{tabular}

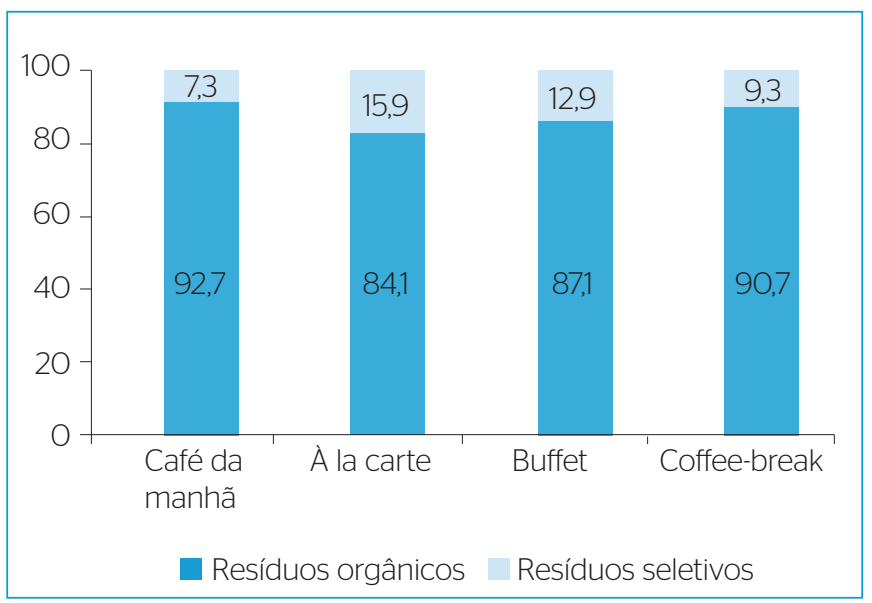

Figura 5 - Resíduos sólidos gerados nas diversas refeições. orgânicos, os quais foram encaminhados para o aterro sanitário do município de Caxias do Sul. Observa-se que poderia ser dado um destino mais nobre a este resíduo, visando o seu aproveitamento, como a compostagem.

Também, a geração de resíduos sólidos e o desperdício de alimentos foram estudados por Naspolini et al. (2009) ao realizarem o diagnóstico da gestão de resíduos sólidos empregada no Restaurante Universitário da Universidade Federal de Mato Grosso (UFMT). Os autores obtiveram que na cozinha $74,75 \%$ dos resíduos eram representados por matéria orgânica putrescível, e o restante por materiais potencialmente recicláveis (plástico, papel, papelão, metal e vidro). Já no refeitório a matéria orgânica putrescível representava $96,48 \%$ dos resíduos e o restante era composto de plástico, papel e papelão.

Além disso, Naspolini et al. (2009) destacam que o desperdício de alimentos representa aproximadamente $15 \%$ da quantidade de alimentos servida, que na amostragem correspondeu a $1.200 \mathrm{~kg}$ de alimentos. Os autores concluem sugerindo a adoção das seguintes práticas para melhorar a eficiência do restaurante: reduzir o tamanho das porções servidas; implementar o sistema de self service (buffet); promover campanhas contra o desperdício; reduzir a produção de resíduos secos (embalagens); implantar o uso de copos de vidros ou acrílico em substituição aos copos plásticos; realizar a segregação dos resíduos potencialmente recicláveis e adquirir produtos em embalagens com maior quantidade.

No que tange ao destino dos resíduos sólidos gerados no âmbito de unidades de alimentação, destacam-se as contribuições de Okazaki, Turn e Flachsbart (2008). No estudo com empreendimentos deste gênero no Hawai (4.854 empreendimentos pesquisados), 1.471 indicaram reaproveitar parte ou todo o resíduo alimentar. Eles indicaram que o método mais comum de reaproveitamento é o encaminhamento desse resíduo para a criação de suínos $(n=625)$. As outras indicações compreenderam a doação dos resíduos alimentares para bancos de alimentos ou para estabelecimentos similares $(n=370)$; o fornecimento para companhias que realizam esse reaproveitamento $(n=188)$; a alimentação de outros animais que não sejam suínos $(n=138)$ e a compostagem $(n=136)$.

O encaminhamento dos resíduos orgânicos para alimentação de suínos ou outros animais apenas seria viável caso os mesmos fossem mantidos e conduzidos em recipientes hermeticamente fechados de uso exclusivo para esse fim, além da garantia de condições de desinfecção, como exige a Lei Estadual nº 6.503 (RIO GRANDE DO SUL, 1972). Isso exigiria uma adequação das práticas atualmente desenvolvidas em relação ao manejo dos resíduos orgânicos no restaurante do meio de hospedagem deste estudo.

Outra alternativa poderia ser a compostagem desse resíduo, originando um composto que poderia ser utilizado na agricultura ou jardinagem. Para tal, é importante avaliar a viabilidade técnica e 
econômica de associar diversos estabelecimentos, na forma de um consórcio, visando a compostagem dos seus resíduos em um único local. Pode-se elencar ainda, como uma alternativa, a degradação anaeróbia desse material em biodigestores ou aterros sanitários com o aproveitamento do biogás para geração de energia.

\section{CONCLUSÕES}

Observou-se que, em muitas situações, o desperdício de alimentos ocorre devido à oferta ser maior do que o consumo de alimentos pelos clientes. Constata-se que é necessária uma readequação do planejamento realizado atualmente no restaurante, buscando reduzir a disparidade observada.

Relatos de alguns colaboradores do meio de hospedagem indicaram que a fartura de alimentos e de opções do cardápio é um indício para os hóspedes da competência e da qualidade do restaurante e dos serviços do meio de hospedagem. Esse pensamento contraria os conceitos de sustentabilidade na gastronomia, havendo a necessidade de promover ações buscando sensibilizar a alta administração, hóspedes e colaboradores de restaurantes sobre os impactos ambientais associados ao desperdício de alimentos e a importância da adoção de técnicas de gestão que permitam minimizar a geração de resíduos sólidos. Entre as técnicas, destaca-se o correto porcionamento das refeições e a compostagem dos resíduos orgânicos, quando a geração dos mesmos é inevitável.

Deve-se avaliar a possibilidade de se adotar na cozinha do hotel, quando possível, a utilização de alimentos de forma integral, por exemplo, utilizando cascas de frutas e talos de legumes. Nesse caso, sugere-se que os hotéis busquem orientação de profissionais da área da Nutrição para que auxiliem na seleção de receitas e nas preparações dos alimentos, visando o mínimo desperdício no seu processamento.

Ainda que de forma limitada, é possível apontar indicadores para avaliação do gerenciamento de resíduos sólidos gerados em restaurantes de meios de hospedagem:

- plano de gerenciamento,

- redução da geração,

- condutas de segregação,

- dispositivos de acondicionamento,

- coleta interna,

- local de armazenamento provisório,

- geração per capita (resíduos/hóspede/dia), entre outros.

Tais indicadores poderão ser alvo de investigação futura, no sentido de aumentar o grau de visibilidade dos sistemas de gestão de resíduos de empreendimentos dessa natureza.

\section{REFERÊNCIAS}

ABREU, E.S.; SPINELLI, M.G.N.; PINTO, A.M.S. (2007) Gestão de unidades de alimentação e nutrição: um modo de fazer. São Paulo: Metha LTDA, 384 p.

BRADACZ, D.C. (2003) Modelo de gestão da qualidade para o controle de desperdício de alimentos em unidades de alimentação e nutrição. 173 f. Dissertação (Mestrado em Engenharia de Produção) Universidade Federal de Santa Catarina, Florianópolis. Disponível em: <http://repositorio.ufsc.br/bitstream/handle/123456789/85188/225881. pdf?sequence=1>. Acesso em: 14 ago. 2006.

BRASIL. (2010) Lei $n^{\circ}$ 12.305, de 02 agosto de 2010. Institui a Política Nacional de Resíduos Sólidos, altera a Lei n 9.605 de 12 de fevereiro de 1998 e dá outras providências. Disponível em: <http://www. planalto.gov.br/ccivil_03/_ato2007-2010/2010/lei/l12305.htm>. Acesso em: 17 ago. 2010.

CRITTENDEN, B.; KOLACZKOWSKI, S. (1995) Waste minimization: a practical guide. Inglaterra: Icheme, $81 \mathrm{p}$.

FONSECA, M.T; BORGES, A.M. de B. (2006) Lixo e hospitalidade: o ensino consciente como estratégia para redução do volume de resíduos produzidos pela indústria de hospitalidade e ferramenta de captação profissional gerando benefício social. In: Seminário de Pesquisa em Turismo do Mercosul,4 Anais... Caxias do Sul: UCS, 2006. 1 CD ROM.
INSTITUTION OF MECHANICAL ENGINEERS - IMechE. (2013) Global Food: Waste Not, Want Not. Londres. Disponível em: <http:// www.imeche.org/docs/default-source/reports/Global_Food_Report. pdf?sfvrsn=0>. Acesso em: 13 ago. 2014.

INSTITUTO DE PESQUISA ECONÔMICA APLICADA - IPEA. (2009) Desperdício - Custo para todos - Alimentos apodrecem enquanto milhões de pessoas passam fome. Desafios do Desenvolviment, ano 6, edição 54 Disponível em: <http://www.ipea.gov.br/desafios/index.php?option=com_co ntent\&view=article\&id=1256:catid=28\&ltemid=23>. Acesso em: 18 set. 2014.

MANDELLI, S.M.D.C. (1997) Variáveis que interferem no comportamento da população urbana no manejo de resíduos sólidos domésticos no âmbito das residências. 267 f. Tese (Doutorado em Educação) Universidade Federal de São Carlos, São Carlos.

MEZOMO, I. de B. (2002) Os serviços de alimentação: planejamento e administração. São Paulo: Manole.

NASPOLINI, B.F.; LUSSI, C.; BORGES, D. De S.; SOUZA, D.B.E; ROCHA, L.A. (2009) Diagnóstico e proposta de melhoria de gestão dos resíduos sólidos produzidos no Restaurante Universitário: Campus Cuiabál UFMT. In: Congresso Brasileiro de Engenharia Sanitária e Ambiental, 25, Anais... Recife: ABES. 1 CD-ROM. 
OKAZAKI, W.K.; TURN, S.Q.; FLACHSBART, P.G. (2008) Characterization of food waste generator: A Hawaii case study. Waste Management, n. 28, n. 12 , p. $2483-2494$.

RIO GRANDE DO SUL. (1972) Lei no 6.503, de 22 de dezembro de 1972. Dispõe sobre a promoção, proteção e recuperação da Saúde Pública. Disponível em: <http://www.al.rs.gov.br/legis/M010/M0100099. ASP?Hid_Tipo=TEXTO\&Hid_TodasNormas $=35819 \& h$ Texto $=\& H_{\text {Hid }}$ IDNorma=35819>. Acesso em: 25 maio. 2007.

SONNINO, R.; McWILLIAM, S. (2011) Food waste, catering practices and public procurement: a case study of hospital food systems in Wales. Food Policy, v. 36, n. 6, p. 823-829. Disponível em: <http://www.sciencedirect. com/science/article/pii/SO3O6919211001163>. Acesso em: 1 jun. 2012.

TEIXEIRA, S.; OLIVEIRA, Z.M.C:; REGO, J.C.; BISCONTINI, T.M.B. (2006) Administração aplicada às unidades de alimentação e nutrição. Rio de Janeiro: Atheneu, $219 \mathrm{p}$.

VENZKE, C.S. (2006) A geração de resíduos em restaurantes analisada sob a ótica da produção mais limpa. Disponível em: <http://www.
abepro.org.br/biblioteca/ENEGEP2001_TR104_0127.pdf>. Acesso em: O5 set. 2006.

VIERA, E.V. de. (2004) Desperdício em hotelaria: soluções para evitar. Caxias do Sul, RS: EDUCS. (Coleção Hotelaria).

WILLIAMS, H.; WIKSTRÖM, F; OTTERBRING, T:; LÖFGREN, M.; GUSTAFSSON, A. (2012) Reasons for household food waste with special attention to packaging. Journal of Cleaner Production, v. 24, p. 141-148. Disponível em: <http://www.sciencedirect.com/science/article/pii/ S0959652611004793>. Acesso em: 13 set. 2013.

WASTE \& RESOURCES ACTION PROGRAMME - WRAP (2013) Understanding out of home consumer food waste. Disponível em: <http://www.wrap.org.uk/sites/files/wrap/OOH\%2OReport.pdf>. Acesso em: 15 set. 2009 .

YOUNGS, A.J.; NOBIS, G.; TOWN, P. (1983) Food waste from hotels and restaurants in the U.K. Waste Management \& Research, v. 1, n. 4, p. 295 308. Disponível em: <http://www.sciencedirect.com/science/article/ pii/0734242X83900344>. Acesso em: 13 set. 2013. 